Relative feed intake, nutrients utilization, nitrogen balance and milk yield of Murrah buffaloes fed organic and inorganically (conventional) produced roughage-concentrate diets

S S Singh, S B Maity, S K Nag

Indian Grassland and Fodder Research Institute, Jhansi, Uttar Pradesh, India

Email: singh.sultan@rediffmail.com

Introduction Organically produced crops are superior in nutritive value and taste and are healthier than inorganically grown crops, as they have less nitrate and better mineral and vitamin contents (Vogtman et al. 1993; Worthington 2001). Positive and negative effects of organic (manure) and inorganic (chemical) fertilizers on nutritional value, sensory quality of produce and animal productivity have been reviewed (Bourn and Prescott 2002). Relative response of organic and inorganically produced feeds and fodder has been assessed in non ruminants and sporadically with ruminants (Roesch et al. 2005). The ultimate test of the nutritional value of any food or fodder depends on its ability to support health, growth and reproduction. The objective of present study was to assess the relative response of organically grown fodder (sorghum hay and berseem) and feeds (barley grain and mustard seed cake) with inorganically produced fodder and feeds on nutrient intake and utilization, $\mathrm{N}$ balance, milk production and nutrient efficiency in lactating Murrah buffaloes.

Materials and methods Ten milch Murrah buffaloes mean weight $(500.7 \pm 7.21 \mathrm{~kg})$, milk yield $(8.2 \pm 0.72$ and $8.0 \pm 0.30$ $\mathrm{kg})$ and lactation stage $(89 \pm 7.02$ and $81 \pm 9.04$ d) equally distributed in G1 and G2. Animals were offered inorganically produced sorghum hay and green berseem fodder with barley grain and MSC concentrate mixture (comprising 60, 37, 2 and 1 parts barley grain, MSC, common salt and mineral mixture, respectively) ingredients in G1 and organically produced sorghum hay and green berseem fodder with barley grain and MSC concentrate mixture ingredients in G2 respectively. Protein and energy requirement for maintenance and milk yield was met through chaffed sorghum hay $(6-9 \mathrm{~kg})$ and berseem $(10 \mathrm{~kg})$ concentrates mixture $(4-4.5 \mathrm{~kg})$. After 60 days of feeding a digestion and metabolism trial was conducted to assess feed intake, nutrients utilization and $\mathrm{N}$ balance, while milk yield and composition was recorded fortnightly for 75 $\mathrm{d}$ of feeding. Proximate constituents and fibre fractions of offered feeds, orts and feces were determined following standard methods. Protein and energy efficiency of diets for milk production was determined by standard equations. The data on different parameters were analyzed statistically (SPPS 13.0) in one way ANOVA using the GLM.

Results Crude protein, DCP, and ME intake ( $\mathrm{g} / \mathrm{kg}$ w0.75) was similar in animals of G1 and G2. NDF, ADF and hemicellulose digestibility was significantly $(\mathrm{P}<0.05)$ higher in animals fed organically grown diets $(\mathrm{G} 2: 59.20,51.55$ and 62.67) than inorganically produced diet (G1: $54.57,43.72$ and $56.61 \%$ Table 1), respectively. Urinary loss (g/d) was significantly lower $(\mathrm{P}<0.05)$ in G2 (67.23) than G1 (83.55), however the $\mathrm{N}$ balance was comparable between both groups. This resulted in higher $\mathrm{N}$ absorption in animals on the organic diet than for those on the inorganic diet (28.08.55 vs 39.72 $\mathrm{g} / \mathrm{d}$ Table 2), but the difference was not significant. Nitrogen retention (\%) was 5 units more in milch buffaloes in G2 than G1. Nutritive value (DCP, TDN and ME) of both diets was similar. No effect of diet was observed on milk yield and its composition. Nutrient conversion ratio and efficiency for milk production was identical on both diets.

Table 1 Nutrients intake and digestibility

\begin{tabular}{llll}
\hline Parameter & $\mathrm{G}_{1}$ & $\mathrm{G}_{2}$ & SEM \\
\hline $\mathrm{DM}(\mathrm{Kg})$ & 10.61 & 10.52 & 0.32 \\
$\mathrm{DM}\left(\mathrm{g} / \mathrm{kg} \mathrm{w}^{0.75}\right)$ & 105.11 & 103.35 & 2.73 \\
$\mathrm{DCP}\left(\mathrm{g} / \mathrm{kg} \mathrm{w}^{0.75}\right)$ & 9.84 & 9.38 & 0.27 \\
$\mathrm{TDN}\left(\mathrm{g} / \mathrm{kg} \mathrm{w}^{0.75}\right)$ & 69.82 & 70.39 & 2.80 \\
$\mathrm{ME}\left(\mathrm{Kcal} / \mathrm{kgw}^{0.75}\right)$ & 0.248 & 0.250 & 0.01 \\
Digestibility $(\%)$ & & & \\
$\mathrm{DM}$ & 60.94 & 62.76 & 0.72 \\
$\mathrm{CP}$ & 69.00 & 67.51 & 1.22 \\
$\mathrm{NDF}$ & 54.57 & 59.20 & 1.08 \\
ADF* & 43.72 & 51.55 & 1.70 \\
Cellulose & 57.42 & 60.72 & 1.45 \\
Hemi-cellulose* & 56.41 & 62.67 & 1.89 \\
\hline \hline
\end{tabular}

Table $2 \mathrm{~N}$ balance and nutrients efficiency

\begin{tabular}{llll}
\hline \hline Parameter & $\mathrm{G}_{1}$ & $\mathrm{G}_{2}$ & SEM \\
\hline N Intake $(\mathrm{g} / \mathrm{d})$ & 229.98 & 226.43 & 5.36 \\
Faeces N & 70.99 & 73.66 & 4.53 \\
Urinary N $(\mathrm{g} / \mathrm{d})^{*}$ & 83.55 & 67.22 & 6.87 \\
Milk N $(\mathrm{g} / \mathrm{d})$ & 47.36 & 45.82 & \\
Balance $(\mathrm{g} / \mathrm{d})$ & 28.08 & 39.72 & 2.12 \\
DCP \% & 9.40 & 9.14 & 0.42 \\
ME $(\mathrm{M} \mathrm{cal} /$ Kg DM) & 2.36 & 2.43 & 0.03 \\
Feed conversion ratio & 1.38 & 1.44 & 0.06 \\
Protein conversion ratio & 188.52 & 194.94 & 12.50 \\
ME conversion ratio & 3.26 & 3.50 & 0.11 \\
Protein efficiency & 29.15 & 30.69 & 1.59 \\
Gross energy efficiency & 44.30 & 44.60 & 3.05 \\
\hline \hline
\end{tabular}

Conclusions It was concluded from the study that organically produced diet tended to have higher fibre digestibility and low urinary $\mathrm{N}$ loss without affecting the milk yield and composition. Diets were also comparable in respect of nutrient conversion and efficiency for milk production.

\section{References}

Bourn, D. Prescott, J.2002. Critical Review Food Science Nutrition, 42 (1), 1-34.

Roesch, M., Dohen, M. G., Blum, J. W. 2005. Journal of Dairy Science. 88, 2462-2475.

Vogtmann, H., MatthiesKehres, B., Meier Ploeger, A. 1993. Compost Science Utilization. 1, 82-100.

Worthington, V. 2001. The Journal of Alternative and Complimentary Medicine. 7(2), 161-173. 
Email: M.HERRERO@CGIAR.ORG

\begin{abstract}
Livestock play a significant role in rural livelihoods and the economies of developing countries. They are providers of income and employment for producers and others working in, sometimes complex, value chains. They are a crucial asset and safety net for the poor, especially for women, and they provide an important source of nourishment for billions of rural and urban households. These socio-economic roles and others, are increasing in importance as the sector grows due to increasing human populations, incomes, and urbanisation rates. To provide these benefits, the sector uses a significant amount of land, water, biomass and other resources and emits a considerable quantity of greenhouse gases. There is concern on how to manage the sector's growth, so that in the future, as availability and access to resources diminishes, these benefits can be attained at a lower environmental cost. Livestock and environment interactions in developing countries can be both positive and negative. On one hand, manures from ruminant systems can be a valuable source of nutrients for smallholder crops, while in more industrial systems, they can be a source of pollution. On the other hand, ruminant systems in developing countries can be considered relatively resource-use inefficient. Due to the high yield gaps in most of these production systems, increasing the efficiency of the livestock sector through sustainable intensification practices, such as improved ruminant nutrition, presents a real opportunity where research and development can contribute to provide more sustainable solutions. In order to achieve this it is necessary that production systems become marketorientated, better regulated in cases, and socially-acceptable, so that the right mix of incentives exists for the systems to intensify. Managing the required intensification is also essential to avoid a potential increase in zoonotic and other diseases.
\end{abstract}




\title{
Challenges in the nutrition and management of herbivores in the temperate zone
}

A $M$ van Vuuren ${ }^{1}$, P Chilibroste $^{2}$

${ }^{1}$ Wageningen UR Livestock Research, P.O. Box 65, 8200 AB Lelystad, the Netherlands, ${ }^{2}$ Faculty of Agronomy, Animal and Pasture Production Department, EEMAC, Ruta 3 km 363, CP 6000, Paysandú, Uruguay.

Email: Ad.vanvuuren@wur.nl

\begin{abstract}
The expected higher global demand for animal proteins and the competition for starch and sugars between food, fuel and feed seem to favour herbivores which convert solar energy captured in fibrous plants into animal products. However, the required higher production level of herbivores questions the sustainability of this conversion. An increase of herbivore production can be achieved by increasingthe number of animals associated with increasing demand of plant biomass or by improving the efficiency by which plant biomass is converted into meat and milk. Potentials to increase food production by cattle, being the main food-producing herbivore in the temperate zones outside China, were considered in three production system: grassland-based, mixed rain-fed, and mixed irrigated systems. Potential to increase plant biomass production in grassland-based systems seems limited, unless fertilizer is imported in large quantities and crop production increased, sacrificing valuable, high quality grasslands, which often conflicts with sustainable production methods. Also in mixed systems with high inputs of fertilizer or water, improvements in plant biomass production seem marginal and main challenge for these systems are to breed high quality plant biomass at lower levels of fertilizer and to use of new restproducts from food processing and biobased economy. Consequently, the main challenge in herbivore nutrition management is to improve the efficiency of plant biomass utilization. Stocking rate management, synchronised with seasonal variation in grazing capacity of grasslands and moderate use of fertilizer may increase meat production in grassland based diets by $400 \%$. Improving plan biomass utilization in the more industrialized mixed rain-fed systems, seems possible by better feed storage technologies and for dairy cattle by improving animal health and lifetime production level. Managing dry-period length and the transition period seem crucial elements to obtain a more sustainable mixed rainfed and mixed irrigated dairy production systems.
\end{abstract}




\title{
Role of herbivores in integrated agriculture in China
}

R Long, X Guo, L Ding, Z Shang

International Centre for Tibetan Plateau Ecosystem Management, Lanzhou University, Gansu 730000, China

Email: Longrj@lzu.edu.cn

\begin{abstract}
In the ancient time of China, horses, cattle, sheep, chicken, dog and hog were regarded as the most important farming animal species to support agricultural activates and farmers' livelihood. Therefore Zhang Tinggui (Tang Dynasty, $712-756$ A.D.) indicated that "People relies on food, food comes from farming, farming relies on cattle". Thus the herbivores provided the fundamental base to drive agriculture in China. However, China today is still a large agricultural nation in terms of its agricultural sector and farmer population in the world. About $51 \%$ of land in China is suffering arid and semiarid climate condition where the Northern pastoral and the Qinghai-Tibetan pastoral zones and Transition zone are distributed (Fig-1). In the pastoral zones herders and farmers rely on those herbivores (cattle, yak, sheep and goats) for maintaining livelihood as the animals provide residents with daily milk and meat consumption and income. In the cropping area of southeastern China, the large herbivores such as cattle, buffalo and horse contribute draught power to farming activities while goats serve as "cash" animals. In the transition zone between pastoral and cropping zones, cattle, beef, sheep and goats are most common animals to provide power and meat products to the consumers. However, before 1950s to 1970 s, the Collective Team was the basic productive unit in countryside, horse, cattle, mule, donkey and buffaloes served mainly as draught animals in cropping and transition areas. While in pastoral areas, cattle, yak, sheep and goats were the basic productive materials and unique resource of income for the herders of Collective Team. Since early 1980 s the Household Contract Responsibility System was initiated across China, Individual farmers or herders households became the basic productive unit, although the draught animals such as mule, donkey and cattle were still kept in the cropping and transition areas. After 2000 these animal were less important for farming activities as tractors became more accessible. However, with less animals, farmers are more inclined to find work off the farm, often in urban areas. In the pastoral area, due to numbers of grazing animals increasing x3 over the past 50 years, rangeland degradation has widely occurred, threatening livelihood of producers. From 1980 to 2009, the livestock share of output values within agricultural sector increased from $18 \%$ to $34 \%$, while the share of crops fell. Management of integrated agriculture in China is better with livestock than without.
\end{abstract}




\title{
Nutrition, immune function and health of herbivores
}

K L Ingvartsen, K Moyes

Department of Animal Science, Aarhus University, Blichers Allé 20, Postboks 50, DK-8830 Tjele, Denmark

E-mail: KlausL.Ingvartsen@agrsci.dk

\begin{abstract}
This review focuses on the interplay between nutrition, immune function and health of herbivores with the dairy cow as the primary focus. The large increase in milk yield and the structural changes in the dairy industry have caused major changes in the housing, feeding and management of e.g. the dairy cow. The quality of roughage has been increased markedly, the proportion of concentrates has been increased and the diet composition has been balanced to accommodate the needs of the modern dairy cow. However, while large improvements have occurred in production and efficiency the disease incidence, based on veterinary records, do not seem to be improved.
\end{abstract}

In earlier reviews it has been argued that certain metabolic states, such as degree of negative energy balance and physiological imbalance and decreased immune competence are key risk factors for non-infectious and infectious diseases in periparturient cows rather than high milk yield per se. Physiological imbalance has been defined as cows whose parameters (reflecting the function of the digestive tract, metabolic state and immune state) deviate from the normal, and who consequently have an increased risk of developing production diseases (clinical or subclinical) and reduced production and/or reproduction.

A number of excellent earlier reviews have covered critical periods such as the transition period in the cow and its influence on health and immune function, the interplay between the endocrine system and the immune system and nutrition and immune function. Knowledge on e.g. such topics are crucial for our understanding of disease risk and our effort to develop health and welfare improving strategies, including proactive management for prevention of diseases and severity of diseases. The main purpose of this review is consequently to review recent research within these areas with special focus on the transition period and physiological imbalance, nutrition and immune function, and to give perspectives for prevention of diseases in the dairy cow.

A majority of the health problems in the dairy cow occur during the periparturient period. To a large extent these health problems relate to cows having difficulty in adapting to the nutrient needs for lactation. This may results in physiological imbalance, a situation where the regulatory mechanisms are insufficient for the animals to function optimally leading to a high risk of a complex of digestive, metabolic and infectious problems. The dramatically increased nutrient demand at the onset of lactation is covered through food intake and nutrients from body stores released through the regulation of body tissues primarily via the endocrine system that plays a key role in the metabolic regulation and nutrient partitioning making priority and support of lactation. The endocrine profile may be influenced by many factors such as e.g. reproductive and lactational state, time around calving, body stores, nutrition and stress but also cross talk between the endocrine end the immune system.

Risk of infectious diseases will be increased if immune competence is reduced. Immune competence may be influenced by a number of factors including e.g. the cross talk between the endocrine and the immune system physiological imbalance and nutrition. Nutrition plays a pivotal role in immune response and nutrients can influence several, if not all, aspects of the immune response. The effect of nutrition may be directly through nutrients or indirectly by metabolites, e.g. in situations with physiological imbalance. This review discusses the complex relationships between metabolic status and immune function and how these complex interactions increase risk of disease during early lactation. A special focus will be placed on the major energetic fuels currently known to be used by immune cells (i.e. glucose, NEFA, BHBA, and glutamine) and how certain metabolic states, such as degree of NEB and risk of PI, contribute to immunosuppression during the periparturient period. Finally, we will address some issues on disease prevention through nutrition. 


\title{
Nutritional impact on performance and health of rabbits
}

J C De Blas

Departamento de Producción Animal, ETS Ingenieros Agrónomos, Universidad Politécnica 28040, Madrid, Spain.

E-mail:c.deblas@upm.es

\begin{abstract}
The present work summarizes research related to the definition of nutrient recommendations for feeds used in the intensive production of rabbit's meat. Fibre is the main chemical constituent of rabbit diets that typically contain 320-360 and 50-90 $\mathrm{g} / \mathrm{kg}$ of insoluble and soluble fibre, respectively. Instead, dietary content of cereal grains (around 120-160 g/kg), fat (15-25 $\mathrm{g} / \mathrm{kg}$ ) and protein concentrates $(150-180 \mathrm{~g} / \mathrm{kg})$ are usually low with respect to other intensively reared monogastric animals. Cell wall constituents are not well digested in rabbits, but this effect is compensated by its stimulus of gut motility, which leads to an increasing rate of passage of digesta, and allows achieving an elevated DM intake. A high feed consumption and an adequate balance in essential nutrients are required to sustain the elevated needs of high productive rabbits measured either as reproductive yield, milk production or growth rate in the fattening period. Around weaning, pathologies occur in a context of incomplete development of the digestive physiology of young rabbits. The supply of balanced diets has also been related with the prevention of disorders by means of two mechanisms: i) promoting a lower retention time 26 of the digesta in the digestive tract through feeding fibre sources with optimal chemical and physical characteristics or ii) causing a lower flow of easily available substrates into the fermentative area by modifying feed composition (e.g. by lowering protein and starch contents, increasing its digestibility or partially substituting insoluble with soluble fibre), or by delaying age at weaning. The alteration of the gut microbiota composition has been postulated as the possible primary cause of these pathologies.
\end{abstract}




\title{
Rumen microbial metagenomics and its application to ruminant production
}

D P Morgavi ${ }^{1}$, W J Kelly², P H Janssen ${ }^{2}$, G T Attwood ${ }^{2}$

${ }^{1}$ INRA UR1213 Herbivores, Site de Theix, F-63122 Saint-Genès-Champanelle, France

${ }^{2}$ AgResearch, Palmerston North, New Zealand

E-mail:morgavi@clermont.inra.fr; graeme.attwood@agresearch.co.nz

\begin{abstract}
Meat and milk produced by ruminants are important agricultural products representing a major source of protein for humans. Ruminant production is of considerable economic value and impacts food security in many regions in the world. However, the sector faces major challenges due to diminishing natural resources and ensuing soaring prices and also due to the increased awareness of the environmental footprint associated with farming ruminants. A better knowledge of the rumen microbiome and its functions will lead to an improvement in the efficiency of feed digestion and the abatement of enteric methane production, and so help meet these challenges to sustainability.

Advances in DNA sequencing technologies and bioinformatics are transforming our understanding of complex microbial ecosystems, including the gastrointestinal tract of mammals. The application of these techniques to the rumen ecosystem have allowed the study of the microbial diversity under different dietary and production conditions. Furthermore, the sequencing of genomes from several individual rumen bacterial and archaeal species have provided detailed information about their physiology. More recently, metagenomics, mainly aimed at understanding the enzymatic machinery involved in the degradation of plant structural polysaccharides, has provided new insights. These advances highlight the promise of these approaches for characterising the rumen microbial community structure and linking this with the functions of the rumen microbiota. Initial results using culture-independent, high-throughput technologies have also shown that the rumen microbiome is far more complex and diverse than the human caecum. Therefore, cataloguing its genes will require a considerable sequencing and bioinformatic effort. Nevertheless, the construction of a rumen microbial gene catalogue through metagenomics and genomics sequencing of key populations is an attainable goal.
\end{abstract}

A rumen microbial gene catalogue is necessary to understand the function of the microbiome and its interaction with the host animal and feeds, and will provide a basis for integrative microbiome-host models and inform strategies promoting less polluting and more robust and efficient ruminants. 
Cattle genome and applications to future nutritional strategy

S Seo ${ }^{1}$, D M Larkin ${ }^{2}$ J J Loor ${ }^{3}$

${ }^{1}$ Department of Animal Biosystem Sciences, Chungnam National University, Daejeon 305-764, Korea, ${ }^{2}$ Institute of Biological, Environmental and Rural Sciences(IBERS), Aberystwyth, University, Aberystwyth, Ceredigion SY23 3DA, UK, ${ }^{3}$ Department of Animal Sciences \& Division of Nutrtional Sciences, University of Illinois at Urbana-Champaign, Urbana, IL 61801, USA

E-mail:swseo@cnu.kr

\begin{abstract}
The recently sequenced cattle (Bos Taurus) genome unraveled the unique genomic features of the species and provided the molecular basis for applying a systemic approach to systematically link genomic information to metabolic traits. Comparative analysis has identified a variety of evolutionary adaptive features in the cattle genome, such as an expansion of the gene families related to the rumen function, large number of chromosomal rearrangements affecting regulation of genes for lactation, and chromosomal rearrangements that are associated with segmental duplications and copy number variations. Metabolic reconstruction of the cattle genome has revealed that core metabolic pathways are highly conserved among mammals although five metabolic genes are deleted or highly diverged and seven metabolic genes are present in duplicate in the cattle genome 26 compared to their human counter parts. The evolutionary loss and gain of metabolic genes in the cattle genome may reflect metabolic adaptations of cattle. Metabolic reconstruction also provides a platform for better understanding of metabolic regulation in cattle and ruminants. A substantial body of transcriptomics data from dairy and beef cattle under different nutritional management and across different stages of growth and lactation are already available and will aid in linking the genome with metabolism and nutritional physiology of cattle. Application of cattle genomics has great potential for future development of nutritional strategies to improve efficiency and sustainability of beef and milk production. One of the biggest challenges is to integrate genomic and phenotypic data and interpret them in a biological and practical platform. Systems biology, a holistic and systemic approach, will be very useful in overcoming this challenge.
\end{abstract}




\title{
Utilization of Biofuels Byproducts as Feedstocks for Ruminants
}

J S Drouillard

Department of Animal Sciences and Industry, Kansas State University, 133 Call Hall, Manhattan, KS 66506-1600, USA

E-mail: jdrouill@ksu.edu

\begin{abstract}
Production of bio-based fuels has expanded dramatically during the last decade, and ramifications of this growth for the livestock industry are becoming increasingly apparent. Conversion of cereal grains to biofuels has increased competition for feedstocks historically used for food animal production, but also has resulted in the availability of large quantities of byproduct feeds that quickly have become dietary staples for livestock. Biofuels byproducts are widely varied in composition, reflecting differences in grains used for fermentation, grain milling processes prior to fermentation, enzymes and yeasts used, antibiotic use for control of bacterial contaminants, continuous versus batch processing, methods for $\mathrm{pH}$ control, and post-fermentation processing of byproduct streams. Moreover, ethanol production processes are evolving rapidly in an attempt to improve economic viability, resulting in an ever-changing composition of byproduct feeds. Production of ethanol from cereal starches and subsequent removal via distillation typically results in the concentration of protein, lipids, minerals, and non-starch carbohydrates within byproducts. Limited shelf-life and high transportation costs for wet byproducts must be balanced with increased energy costs for drying to produce shelf-stable byproducts. Wet and dried distiller's grains constitute valuable sources of energy, protein, and minerals when used as livestock feeds, though information related to their optimal use is generally lacking. Distiller's grains can be highly complementary when used judiciously as supplements to forage-based diets, providing essential energy and nutrients that often are lacking in forages. Widespread availability and favorable pricing of ethanol byproducts in some geographical regions has, however, encouraged excessive feeding of protein and phosphorus to ruminants, exacerbating negative environmental consequences of large-scale production systems. As with nutrients, mycotoxins from cereal feed stocks also are concentrated within byproducts, and residues of antibiotics used during fermentation may be present. Utilization of sulfur-containing acids for $\mathrm{pH}$ control and cleaning of fermentation systems often yields high sulfur concentrations in byproducts, and can have deleterious consequences for animal productivity and well-being. Residual sulfur is reduced to $\mathrm{H} 2 \mathrm{~S}$ by ruminal microorganisms, eructated, and subsequently aspirated into the lungs, and when in excess can induce polioencephalomalacia. Feeding modest to high levels of distiller's grains also can alter gut ecosystems, encouraging colonization by pathogenic Escherichia coli and ultimately increasing shedding of these organisms in manure. Improving our understanding of the impact of ethanol byproducts on microbial ecology, digestive processes, nutritional requirements, animal health, productivity, and the environment will be essential for optimizing their use and for achieving sustainability of the biofuels industry.
\end{abstract}




\title{
Sustainable management for rangelands in a variable climate: evidence and insights from northern Australia
}

P J O'Reagain ${ }^{1}$, J C Scanlan ${ }^{2}$

${ }^{1}$ Department of Employment, Economic Development and Innovation, 6 PO Box 976, Charters Towers, Q4820, Australia, ${ }^{2}$ Department of Employment, Economic Development and Innovation, PO Box 102, Toowoomba, Q4350, Australia.

E-mail:Peter.O'Reagain@deedi.qld.gov.au

\begin{abstract}
Inter-annual rainfall variability is a major challenge to sustainable and productive livestock management on most rangelands. The problem is particularly pronounced in Australia and failure to manage for this phenomenon results in major economic loss and environmental degradation. In this paper we present learnings and insights gained from empirical research, simulation modelling and general experience in managing for rainfall variability in northern Australia.

Managing for rainfall variability in this environment is particularly difficult with extensive spatially heterogeneous paddocks, large cattle herds and limited infrastructure. Recommended stocking strategies like 24 conservative or variable stocking are conceptually simple but difficult to implement because of these issues, as well as the uncertainty about rainfall in the next season and the effects of herd structure changes on longer term profitability. A method to objectively estimate long term carrying capacity (LTCC) in large paddocks based on simulation modelling is discussed while various methods and tools to tactically adjust stocking rates as rainfall varies are presented. The possible use of seasonal climate forecasts in informing stocking decisions is also considered.
\end{abstract}

Empirical grazing trials at an appropriate scale for these rangelands have also been important in developing better stocking strategies to manage for variability. Results from a 14 year grazing trial confirm that constant heavy stocking was unprofitable and not sustainable. Conservative stocking at LTCC was far more profitable and largely maintained land condition. Variable stocking with or without the use of seasonal climate forecasts was marginally more profitable than conservative stocking but income variability was greater and land condition poorer. Spelling of pastures did little to even out inter-annual variability of available forage flow but had positive effects on pasture condition. Two other large grazing trials with breeders provided some evidence that heavier pasture utilisation rates depress reproductive performance. Both trials demonstrated the practical difficulties associated with variable stocking at a commercial scale.

Simulation modelling also showed a decline in resource condition and profitability under high stocking rates. Modelling further suggested that the relative value of variable vs. constant stocking depends upon stocking rate and land condition. Importantly, variable stocking may possibly allow slightly higher stock rates without pasture degradation. Simulations run for breeder herds at the enterprise level nevertheless show that degradation can occur under both constant and variable stocking.

It is recommended that a form of constrained flexible stocking be applied to manage for climate variability, with upper limits based on LTCC set on stocking rates and stocking rate changes between years. Active adaptive management and research will be required as future climate changes make the issue of managing for rainfall variability increasingly challenging. 


\title{
Managing variations in dairy cow nutrient supply under grazing
}

J L Peyraud, R Delagarde

INRA, UMR1080, Production du Lait, F-35590 Saint-Gilles, France, Agrocampus Ouest, UMR1080, Production du Lait, F-35590 Saint-Gilles, France

E-mail: jean-louis.peyraud@rennes.inra.fr

\begin{abstract}
The dairy sector has to adapt to a greater volatility of prices, to the projected increase in energy and fertiliser prices and to environmental stakes. In this context, grazed pasture, which is the cheapest source of nutrients for dairy cows, should form the basis of profitable and low inputs animal production systems. Management of high producing dairy cows at pasture is thus a major challenge in most European countries. The objective of the present paper is to review the factors which can affect nutrient supply for grazing dairy cows in order to point out areas with scope for improvement on managing variations in nutrient supply to achieve high animal performance while maintaining efficient pasture utilisation per hectare. Reviewing the range in animal requirements, intake capacity and pasture nutritive values shows that high producing cows cannot satisfy their energy requirements from grazing alone and to classify favourable to unfavourable situations for grazing dairy cows. Predictive models also enable to calculate supplementation level required to meet energy requirements in all situations. Solutions to maintain acceptable level of production per cow and high output per ha are discussed. Strategies of supplementation with concentrates and/or forages and the more systematic use of legumes in mixed swards are the most promising. It is concluded that although high producing cow can not express their milk potential at grazing; there is scope to improve animal performances at grazing given recent developments in our understanding of factors influencing forage intake and digestion of grazed forages.
\end{abstract}


Breeding for genetic improvement of forage plants in relation to increasing animal production with reduced environmental footprint

A H Kingston-Smith, A H Marshall, J M Moorby

IBERS, Aberystwyth University, Gogerddan, Aberystwyth SY23 3EB. UK.

E:mail:ahk@aber.ac.uk

\begin{abstract}
Animal production is a fundamental component of the food supply chain, and with an increasing global population production levels are set to increase. Ruminant animals in particular are valuable in their ability to convert a fibre-rich forage diet into a high quality protein product for human consumption, although this benefit is offset by inefficiencies in ruminal fermentation which contribute to emission of significant quantities of methane and nitrogenous waste. Through cooperation between plant and animal sciences, we can identify how the nutritional requirements of ruminants can be satisfied by high quality forages for the future.

Selective forage plant breeding has supported crop improvement for nearly a century. Early programmes were successful in terms of yield gains (4-5\% per decade), with quality traits becoming increasingly important breeding targets (eg. enhanced disease resistance and digestibility). Recently, demands for more sustainable production systems have required high yielding, high quality forages that enable efficient animal production with minimal environmental impact. Achieving this involves considering the entire farm system and identifying opportunities for maximising nutrient use efficiency in both forage and animal components. Forage crops of the future must be able to utilise limited resources (water and nutrients) to maximise production on a limited land area, which may require us to consider alternative plant species. Furthermore, new breeding targets will be identified as the interactions between plants and the animals that consume them become better understood. This will ensure that available resources are targeted at delivering maximum benefits to the animal through enhanced transformation efficiency.
\end{abstract}


Advances in Predicting Nutrient Partition in the Dairy Cow: Recognizing the Central Role of Genotype and its Expression through Time

N C Friggens ${ }^{1,2}$, L Brun-Lafleur ${ }^{3,4,5}$, P Faverdin ${ }^{3,4}$, D Sauvant ${ }^{1,2}$, O Martin ${ }^{1,2}$

${ }^{1}$ INRA, UMR 791 Modélisation Systémique Appliquée aux Ruminants, 16 rue Claude Bernard, 75005 Paris, France, ${ }^{2}$ AgroParisTech, UMR 791 Modélisation Systémique Appliquée aux Ruminants, 16 rue Claude Bernard, 75005 Paris, France, ${ }^{3}$ INRA, UMR1080 Production du Lait, F-35590 Saint-Gilles, France, ${ }^{4}$ Agrocampus-Ouest, UMR1080 Production du Lait, F-35000 Rennes, France, ${ }^{5}$ Institut de l'Élevage, F-35652 Le Rheu, France

E mail: nicolas.friggens@agroparistech.fr

\begin{abstract}
In recent years it has become increasingly clear that understanding nutrient partitioning is central to a much broader range of issues than just being able to predict productive outputs. The extent to which nutrients are partitioned to other functions such as health and reproduction is clearly of major importance, as are the efficiency consequences of nutrient partitioning. Further, given the increase in environmental variability, there is an increasing need to be able to predict the ability of an animal to respond to the nutritional challenges that arise from the environment in which it is placed. How the animal partitions its nutrients when resources are limited, or imbalanced, is a major component of its ability to cope, i.e. its robustness. There is mounting evidence that reliance on body reserves is increased and that robustness of dairy cows is reduced by selection for increased milk production. A key element for predicting nutrient partition in this wider context is to incorporate the priorities of the animal i.e., an explicit recognition of the role of genotype and its expression through time on nutrient partitioning. Accordingly, there has been a growing recognition of the need to incorporate in nutritional models the innate driving forces that alter nutrient partitioning according to physiological state; the genetically driven trajectories. This paper summarizes some of the work carried out to extend nutritional models to incorporate these trajectories, genetic effects on them, and how these factors affect the homeostatic capacity of the animal. There are now models capable of predicting nutrient partition throughout lactation for cows of differing milk production potentials. Information concerning genotype and stage of lactation effects on homeostatic capacity has not yet been explicitly included in metabolic models that predict nutrient partition, although recent experimental results suggest that this is achievable. These developments have greatly extended the generality of nutrient partitioning models with respect to the type of animal and its physiological state. However, these models remain very largely focussed on predicting partition between productive outputs and body reserves and, for the most part, these models remain research models although substantial progress has been made toward developing models that can be applied in the field. The challenge of linking nutrient partition prediction to its consequences on health, reproduction, and longevity, although widely recognized, is only now beginning to be addressed. This is an important perspective for future work on nutrient partitioning.
\end{abstract}


Moving from nutritional physiology to nutritional ecology: The opportunity for emerging telemetry technologies in herbivore nutrition studies

D L Swain ${ }^{1}$, M A Friend ${ }^{2}$

${ }^{1}$ Centre for Environmental Management, CQUniversity, Rochampton, QLD, 4701,Australia, ${ }^{2} \mathrm{EH}$ Graham Centre for Agricultural Innovation, School of Animal and VeterinarySciences, 10 Charles Sturt University, Wagga Wagga, NSW, 2678, Australia

Email:d.swain@cqu.edu.au

\begin{abstract}
The principles of herbivore nutrition are well understood and have been developed through detailed physiological studies. However methods to accurately measure field based intake still challenge herbivore nutrition research. Nutritional ecology considers an animal's interaction with the environment based on its nutritional demands. Whilst there are a number of theoretical frameworks that can be used to explore nutritional ecology optimal foraging provides a suitable starting point. Optimal foraging models have progressed from deterministic techniques to spatially explicit agent based simulation techniques. The development of optimal foraging modelling points towards opportunities' for field based research to explore behavioural preferences within studies that have an array of nutritional choices that vary both spatially and temporally. A number of techniques including weighing animals, weighing herbage, using markers (both natural and artificial) and sampling forage using oesphogaelly fistulated animals have been used to determine intake in the field. These intake measurement techniques are most suited to studies that occur over a few days and with relatively small groups of animals (up to 10 animals at a time). Over the last ten years there have been a number of advances in automated behavioural monitoring technology e.g. global positioning systems to track animal movement. A number of recent studies have integrated detailed spatial assessments of vegetation using on ground sampling and satellite remote sensing, these data have been linked to behavioural preferences of herbivores. Whilst the recent studies still do not address nutritional interactions over months or years they do point to methods that could be used to address and landscape scale nutritional interactions. Emerging telemetry techniques used to monitor herbivore behavioural preferences and also to determine detailed landscape vegetation mapping provide the opportunity for future herbivore nutritional ecology studies.
\end{abstract}




\title{
Biophysical drivers of global livestock greenhouse gas emissions and production
}

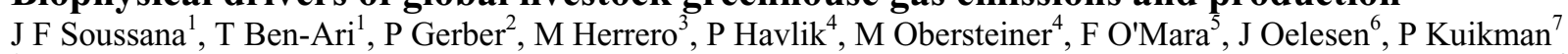

${ }^{1}$ INRA, UR0874 Grassland Ecosystems Research, 234 Avenue du Brézet, Clermont-Ferrand, F-63100, France, ${ }^{2}$ Food and Agriculture Organisation of the United Nations (FAO), Livestock Environment and Development (LEAD) Initiative, 00100 Rome, Italy, ${ }^{3}$ International Livestock Research Institute, P.O. Box 30709, Nairobi, Kenya, ${ }^{4}$ International Institute for Applied Systems Analysis, Laxenburg, Austria, ${ }^{5}$ Teagasc, Agriculture Research, Head Office, Oak Park, Carlow, Ireland, ${ }^{6}$ University of Aarhus, Inst. of Agroecology and Environment, Box 50, 8830 Tjele, Denmark, 7Alterra, Wageningen University and Research Centre, P.O. Box 47, 6700 AA, Wageningen, The Netherlands

E-mail: jfsoussana@clermont.inra.fr

\begin{abstract}
We analyse past (1970-2009) trends in global livestock greenhouse gas (GHG) emissions and production by developing identities that link the demand for animal food, the supply of animal products and the resulting GHG emissions. We first breakdown the global supply and demand of animal proteins, into intensive variables combining: diet (protein intake per capita, fraction of animal proteins, food waste), livestock production (protein conversion efficiency per livestock category), feed quality (protein contents), yields (potential yield and yield gap) and land use for arable and grasslands. Since supply and demand of animal products are equal at a global scale, we show that population density is constrained by these intensive variables. With further assumptions, we estimate trends in greenhouse gas emissions and removals (i.e. carbon sequestration in soils) from the livestock sector in $\mathrm{CO}_{2}$ equivalents. We show that while the global livestock protein production has been multiplied by 2.5 since 1970, the corresponding GHG emissions from the sector (not including emissions associated to land use change and to lifecycle) have presumably been increased by $70 \%$ only. The corresponding decline in GHG emissions per unit protein can be ascribed to the transition towards monogastrics, to the increase in animal production efficiencies and to the rise in yields. We further discuss how to develop storylines for the livestock sector based on this approach and how to couple such storylines with climate scenarios and with adaptation and mitigation options within the framework of the EC FP7 AnimalChange project (www.animalchange.eu).
\end{abstract}


Strategies to mitigate nitrous oxide emissions from herbivore production systems

R L M Schils ${ }^{1}$, J Eriksen ${ }^{2}$, S Ledgard ${ }^{3}$, Th V Vellinga ${ }^{4}$, P J Kuikman ${ }^{1}, \mathrm{~J} \mathrm{Luo}^{3}$, S O Petersen ${ }^{2}$, G L Velthof ${ }^{1}$

${ }^{1}$ ALTERRA, Wageningen-UR, PO Box 47, 6700 AA Wageningen, The Netherlands, ${ }^{2}$ Department of Agroecology and Environment, University of Aarhus, PO Box 50, Tjele, Denmark, ${ }^{3}$ AgResearch Ltd., Ruakura Research Centre, Private Bag 3123, Hamilton, New Zealand, ${ }^{4}$ Livestock Research, Wageningen-UR, PO Box 65, 8200 AB Lelystad, The Netherlands E-mail: rene.schils@wur.nl

\begin{abstract}
Herbivores are a significant source of nitrous oxide $\left(\mathrm{N}_{2} \mathrm{O}\right)$ emissions. They account for a large share of manure related $\mathrm{N}_{2} \mathrm{O}$ emissions, as well as soil related $\mathrm{N}_{2} \mathrm{O}$ emissions through the use of grazing land, and land for feed and forage production. It is widely acknowledged that mitigation measures are necessary to meet the growing global food demand without increasing $\mathrm{N}_{2} \mathrm{O}$ emissions. The production and emission of $\mathrm{N}_{2} \mathrm{O}$ is closely linked to the efficiency of $\mathrm{N}$ transfer between the major 26 components of a livestock system, i.e. animal, manure, soil and crop. Therefore, mitigation options in this paper have been structured along these $\mathrm{N}$ pathways. Mitigation technologies involving diet-based intervention include lowering the crude protein content or increasing the condensed tannin content of the diet. Animal related mitigation options also include breeding for improved $\mathrm{N}$ conversion and high animal productivity. In liquid manures, there is generally little potential for $\mathrm{N} 2 \mathrm{O}$ formation. The main soil based mitigation measures are an efficient use of fertilizer and manure, including the use of nitrification inhibitors. In pasture based systems with housing facilities, reducing grazing time is an effective option to reduce $\mathrm{N}_{2} \mathrm{O}$ losses. Crop based options comprise breeding efforts for increased $\mathrm{N}$ use efficiency and the use of pastures with clover. It is important to recognize that all $\mathrm{N}_{2} \mathrm{O}$ mitigation options affect the nitrogen and carbon cycles of livestock systems. Therefore, care should be taken that reductions in $\mathrm{N}_{2} \mathrm{O}$ emissions are not offset by unwanted increases in $\mathrm{NH}_{3}$, $\mathrm{CH}_{4}$ or $\mathrm{CO}_{2}$ emissions. Despite the abundant availability of mitigation options, implementation in practice is still lagging. Actual implementation will only follow after increased awareness among farmers and greenhouse gases targeted policies. So far, reductions in $\mathrm{N}_{2} \mathrm{O}$ emissions that have been achieved are mostly a positive side-effect of other $\mathrm{N}$ targeted policies.
\end{abstract}


Nutritional and host effects on methanogenesis in the ruminant

Harry Clark

New Zealand Agricultural Greenhouse Gas Research Centre

Grasslands Research Centre, Tennent Drive

Private Bag 11008, Palmerston North 4442, New Zealand

T: +64 $63518111 \mid$ F: +64 63518333

E-mail: harry.clark@nzagrc.org.nz

ABSTRACT: Concentrations of methane in the atmosphere have almost doubled since the mid 1700's and it is estimated that approximately $30 \%$ of the global warming experienced by the planet in the last century and a half can be attributed to methane. Between 25 and 40\% of anthropogenic methane emissions are estimated to arise from livestock farming. Mitigating absolute emissions from livestock is extremely challenging technically and is made more difficult due to the need to increase food production to meet the demands of a burgeoning world population. Manipulating the diet of ruminant can reduce absolute methane but in grazing livestock the opportunities to do this are constrained practically and economically. Mitigating emissions per unit of product is more tractable, especially in the short term. Although the formation of methane is an anaerobic microbiological process the host animal does seem to exert an influence since animals differ in the quantity of methane they emit when fed the same diet. The reasons for this are not yet clear but, in some animals at least, these differences seem consistent and have a genetic basis. Exploiting these between animals differences by animal breeding is an attractive mitigation option since it is potentially applicable to all animals and is open to continuous improvement. However, identifying the desired phenotype poses severe practical constraints. Vaccinating the host animal to produce antibodies that can modulate the activities of the organisms responsible for methane formation also presents a novel mitigation option. (Key Words: methane, diet, ruminant, breeding, antibodies, vaccination) 


\title{
Diversity of gut methanogens in herbivorous animals
}

A-D Wright, B St-Pierre

Department of Animal Science, University of Vermont (UVM), Burlington, Vermont 05405, USA

E-mail: agwright@uvm.edu

\begin{abstract}
The digestion of plant biomass by symbiotic microbial communities in the gut of herbivore hosts also results in the production of methane, a greenhouse gas that is released into the environment where it contributes to climate change. Since methane is exclusively produced by methanogens, various research groups have devoted their efforts to investigate the population structure of symbiotic methanogens in the gut of herbivores. In order to uncover trends that would facilitate the development of efficient methane mitigation strategies for livestock species, we summarized and compared the currently available results from previously published studies on this subject as well as unpublished results from our group.
\end{abstract}

Material and methods Information on methanogen population structure from the gut of herbivorous animals was obtained from published peer-reviewed reports using 16S rRNA gene clone libraries as method for their investigation. For each condition or factor analysed, i.e. either host species, breed or diet, we designated clones as belonging to a valid methanogen species if its sequence identity was at least $98.0 \%$, as an unassigned species of a genus for 95.0 to $97.9 \%$ sequence identity, or as belonging to a phylum if lower than $95.0 \%$. The representation of each category was determined as a percentage of the total number of clones identified in its corresponding study.

Table 1. Methanogen population structure in various host species, breeds or in response to dietary treatments. Representation is expressed as a percentage (\%) of the total number of clones identified in the study.

\begin{tabular}{|c|c|c|}
\hline Host & \# clones & Methanogen population structure \\
\hline Alpaca $^{1}$ & 947 & Mbr. millerae (47.3\%), unassigned Mbr. (21.1\%) \\
\hline Bactrian camel $^{1}$ & 108 & unassigned $M b r .(92.6 \%)$ \\
\hline Beef cattle (corn) $)^{2}$ & 127 & Mbr. ruminantium (48.0\%), novel order (46.1\%) \\
\hline Beef cattle (potato) ${ }^{2}$ & 114 & Novel order (50.0\%), Mbr. ruminantium (21.1\%), unassigned $M b r .(19.3 \%)$ \\
\hline Buffalo (corn) ${ }^{1}$ & 244 & unassigned $M b r .(46.7 \%), M b r$. ruminantium $(30.3 \%)$ \\
\hline Buffalo (pasture) ${ }^{1}$ & 119 & Mbr. millerae (41.2\%), unassigned $M b r .(32.8 \%)$ \\
\hline Buffalo (sugarcane) $^{1}$ & 104 & Mbr. millerae (33.3\%), Mbr. ruminantium (32.7\%), unassigned Mbr. (21.2\%) \\
\hline Buffalo (Murrah) ${ }^{3}$ & 108 & Methanomicrobium mobile (94.4\%) \\
\hline Buffalo (Surti) ${ }^{4}$ & 171 & unassigned Methanomicrobiales (97.1\%) \\
\hline Chicken $^{5}$ & 420 & Mbr. woesei $(96.7 \%)$ \\
\hline Dairy cattle (Holstein $)^{6}$ & 166 & unassigned $M b r . \quad(87.3 \%)$ \\
\hline Dairy cattle (Holstein $)^{7}$ & 152 & Mbr. millerae $(73.0 \%)$ \\
\hline Dairy cattle (Holstein) ${ }^{8}$ & 41 & unassigned Mbr. (37\%), unassigned Methanosphaera (26.8\%), Mbr. Ruminantium $(21.2 \%)$ \\
\hline Dairy cattle (Holstein) ${ }^{9}$ & 180 & unassigned $M b r .(47.8 \%), M b r$. ruminantium $(28.3 \%)$, Mbr. millerae $(16.7 \%)$ \\
\hline Dairy cattle (Jersey) ${ }^{9}$ & 185 & Mbr. millerae (34.6\%), Mbr. ruminantium (33.0\%), unassigned $M b r .(28.6 \%)$ \\
\hline Dairy cattle (Jersey) ${ }^{10}$ & 15 & unassigned Methanosphaera $(33.3 \%)$, Mbr. ruminantium $(33.3 \%)$ \\
\hline Hoatzin $^{11}$ & 197 & Mbr. ruminantium (64.5\%), unassigned $M b r .(21.3 \%)$ \\
\hline Reindeer $^{12}$ & 97 & Novel order $(53.0 \%)$, unassigned $M b r .(28.0 \%)$ \\
\hline Sheep (Australia) ${ }^{13}$ & 78 & Novel order $(80.8 \%)$ \\
\hline Sheep (Venezuela) ${ }^{14}$ & 104 & Mbr. gottschalkii (38.5\%), Mbr. ruminantium (32.7\%), Mbr. thaurei (19.2\%) \\
\hline Wallaby (May) ${ }^{15}$ & 95 & Mbr. gottschalkii $(91.6 \%)$ \\
\hline Wallaby (November) ${ }^{15}$ & 96 & Novel order $(91.7 \%)$ \\
\hline $\mathrm{Yak}^{16}$ & 14 & Mbr. NT7 (78.6\%) \\
\hline
\end{tabular}

Entries are shown in table if greater than $15.0 \%$. Numbers in superscript correspond to references provided below.

These comparisons highlight the strong influence of host species and diet in the determination of the population structure of symbiotic methanogens, and also reveal complex interactions, such as differences between breeds as well as unexpected similarities between unrelated species. These observations strongly support the need for high throughput sequencing and metagenomics to gain further insight.

References 1. Wright, A.-D.G. unpubl; 2. Wright et al. 2007. Appl. Environ. Microbiol (AEM). 73, $4206-4210 ; 3$. Chaudhary et al.,2009. Lett. Appl. Microbiol. 49, 274-277; 4. Singh et al. 2011 Res. Vet. Sci. DOI:10.1016/j.rvsc.2011.1003.1022; 5. Saengkerdsub et al 2007. AEM. 73, 353-356; 6. Hook et al 2009. AEM. 75, 374380; 7. Hook et al 2011 DOI.1007/ s00248-011-9881-0; 8. Whitford et al 2001. BMC Microbiol. 1, 1-5; 9. King et al 2011. DOI 10.1128/AEM.05130-11; 10. Skillman et al 2006. Lett. Appl. Microbiol. 42, 222-228; 11. Wright et al. 2009. ISME J. 3, 1120-1126; 12. Sundset et al 2009. FEMS Microbiol. Ecol. 70, 553-562; 13. Wright et al 2006. Anaerobe 12, 134-139; 14. Wright et al 2008. Microb. Ecol. 56, 390-394; 15. Evans et al., 2009. AEM. 75, 2598-2602; 16. An et al. 2005. Anaerobe 11, 207-215. 


\title{
Developments in altering the fatty acid composition of ruminant-derived foods
}

K J Shingfield ${ }^{1}$, M Bonnet ${ }^{2}$, N D Scollan ${ }^{3}$

${ }^{1}$ MTT Agrifood Research, Animal Production Research, FI-31600, Jokioinen, Finlan, ${ }^{2}$ INRA, UR1213 Herbivores Research Unit, F-63122 Saint-Genès-Champanelle, France, ${ }^{3}$ Institute of Biological, Environmental and Rural Sciences, Aberystwyth University, Gogerddan Campus, Aberystwyth, SY23 3EB, UK.

E-mail: kevin.shingfield@mtt.fi

\begin{abstract}
There is increasing evidence to indicate that nutrition is an important environmental factor involved in the onset and development of several chronic human diseases including cancer, cardiovascular disease (CVD), type 2 diabetes and obesity. A major development has been the recognition of the important role of lipids in the human diet on health maintenance. Clinical and biomedical studies have implicated excessive consumption of medium-chain saturated fatty acids (SFA) and trans fatty acids (TFA) as risk factors for CVD, with increasing evidence to suggest a possible role in the aetiology of other chronic conditions. Ruminant-derived foods are significant sources of medium-chain SFA and TFA, but also provide high quality protein, energy, minerals and other essential micronutrients in the human diet. Furthermore, ruminant meat and milk also contain several bioactive lipids including cis-9, trans-11 conjugated linoleic acid (CLA), $18: 2 n-6,18: 3 n-3,20: 5 n-3$ and to a lesser extent 22:6n-3. Therefore there has been considerable interest in altering the fatty acid composition of ruminant meat and milk to improve long-term human health. An extensive amount of research has demonstrated that it is possible to lower the concentrations of SFA in milk fat and increase the levels of certain potentially beneficial fatty acids, principally through changes in the diet of lactating cows that include replacing conserved with fresh forages and the use of plant oil, oilseed and marine lipid supplements. Studies in growing ruminants have also shown that the same nutritional strategies can be used to improve the balance of $n-6 / n-3$ polyunsaturated fatty acids (PUFA), and increase CLA and long-chain n-3 in ruminant meat, but the potential to lower SFA is limited. Alterations in meat and milk fatty acid composition to changes in diet composition are also accompanied by higher TFA concentrations. Significant advances have been made during the last decade in understanding the formation and accumulation of TFA biohydrogenation intermediates in the rumen, and characterising the impact of diet, production system and genotype on the relative abundance of isomers of TFA in ruminant-derived foods. Recent investigations have also reported significant genetic variability of milk fat and tissue lipid composition in cattle and identified several single nucleotide polymorphisms, that may, at least in part, contribute to this variance. Application of molecular techniques have also revealed that dietaryinduced changes in milk fat or muscle lipid composition are often accompanied by tissue-specific alterations in the abundance of transcripts encoding for one or more lipogenic genes. A much more detailed and fundamental understanding of the molecular and biochemical mechanisms involved in mammary and tissue lipogenesis, combined with characterizing lipogenic gene responses to specific nutrients, has highlighted future opportunities to alter the fatty acid composition of ruminant-derived foods through genomic selection and formulation of diets to exploit this genetic potential.
\end{abstract}


Dietary fatty acids and cardiovascular disease

A M Salter

Division of Nutritional Sciences, School of Biosciences, University of Nottingham, Sutton Bonington Campus, Loughborough, Leicestershire LE12 5RD

E-mail: Andrew.Salter@nottingham.ac.uk

\begin{abstract}
s
In 1991 the Committee on Medical Aspects of Food Policy produced a report on the dietary reference values for food energy and nutrients for groups of people in the United Kingdom. The resulting recommendations, which included specific limits for intakes of total, saturated, trans and cis-polyunsaturated fatty acids (PUFA) have remained a cornerstone of public health policy ever since and similar recommendations have been adopted by the World Health Organisation. These recommendations were made largely on the basis of specific effects of these fatty acids on risk of developing atherosclerotic cardiovascular disease (CVD). The intervening years have seen a plethora of human epidemiological and intervention trials to further elucidate the specific relationship between dietary fatty acid intake, plasma lipids and lipoproteins and cardiovascular morbidity and mortality. A number of recent meta-analyses and systematic reviews have revisited the role of specific dietary fatty acid classes and CVD risk. In general these continue to support a link between saturated fatty acids and CVD morbidity/mortality. They also highlight the potent adverse effects of trans fatty acids derived from partially hydrogenated vegetable oil. The most recent data suggests that replacing saturated fatty acids with cis -PUFA (primarily linoleic acid) has the greatest impact on reducing CVD risk. Evidence of specific beneficial effects of n-3 PUFA is generally stronger for secondary, rather than primary, CVD risk and is restricted to very long chain fatty acids of marine origin as opposed to alpha -linolenic acid. Taken together this data suggests that recent focus on dietary n6 to n-3 PUFA ratios may have been misguided and that future strategies should focus on replacing dietary saturated fatty acids with n-6 PUFA.
\end{abstract}




\title{
The role of herbivores in securing food security
}

\section{Gill}

School of Geosciences, College of Physical Sciences, University of Aberdeen, Fraser Noble Building, Kings College, Aberdeen AB24 3UE, Scotland, UK

Email:m.gill@abdn.ac.u

\begin{abstract}
"Food security exists when all people, at all times, have physical and economic access to sufficient, safe and nutritious food to meet their dietary needs and food preferences for an active and healthy life." (World Food Summit 1996). Humans have depended on animals since pre-history. Not just as direct sources of food, but also for other functions vital for survival (and hence indirectly contributing to food security) such as wool, skins and dung to provide warmth, manure to fertilise crops, power for transport and cultivation and, more recently, as a source of income. The relationship between animals and people changes, however, as a country's economy grows: food and income become more dominant. As the global economy has grown, so too has the demand for edible livestock products: per capita consumption of meat has increased from 30.0 $\mathrm{kg} /$ capita/yr in 1980 to $41.2 \mathrm{~kg} / \mathrm{capita} / \mathrm{yr}$ in 2005 (FAO, 2009). This increasing consumption will be magnified in future by the growth in global population: predicted to rise to 9 billion by 2050 . Increasing population is just one of the pressures on the global food system: the effects of climate change and competition for land, water and energy are other key challenges highlighted by the UK Government Office for Science in their study on the future of food and farming (Foresight 2011). Taking such challenges into account presents a complex picture of the impacts of herbivores on food security and in Table 1 , just a few direct and indirect (through climate change) impacts are presented for illustration. Some of these impacts (particularly the negative ones) have been easier to quantify than others and quantification of key negative impacts in Livestock's Long Shadow (Steinfeld et al. 2006) led (in some developed countries) to a lobby against meat consumption, as if food was the only way in which humans benefit from livestock.
\end{abstract}

Table 1 Impacts of herbivores on food security

\begin{tabular}{|l|l|}
\hline Negative impacts of herbivores on food security & Positive impacts of herbivores on food security \\
\hline Direct & Food from land which can't support crops \\
\hline Inefficient use of grain in intensive livestock systems & High quality nutrients in subsistence level consumption \\
\hline Excessive consumption of meat causes health problems & Saving of oil through use of draught power \\
\hline Indirect via climate change & Carbon sequestration by pasture \\
\hline Production of $\mathrm{CH}_{4} \& \mathrm{~N}_{2} \mathrm{O}$ &
\end{tabular}

Complexity does not make for easy decision making between options for lower-carbon lifestyles. Hence many commentators have simplified the interactions of livestock production and food security down to inefficient use of grain and/or production of methane, to justify encouraging ethical humans to eat less meat. Such commentaries ignore the fact that both of these impacts vary considerably between livestock systems and that ethical consumption can be helped by changing management practices. The figure below uses a schematic (i.e. the area enclosed by the dotted line in each quadrant is indicative only) to illustrate the pluses and minuses of extensive vs intensive systems using 4 possible metrics. Extensive systems are good for carbon sequestration and preserving arable land, while intensive systems produce more food/ha with lower emissions/product.

Balancingfood security \& climate impacts: extensive systems

Balancingfood security \& climate impacts: intensive systems
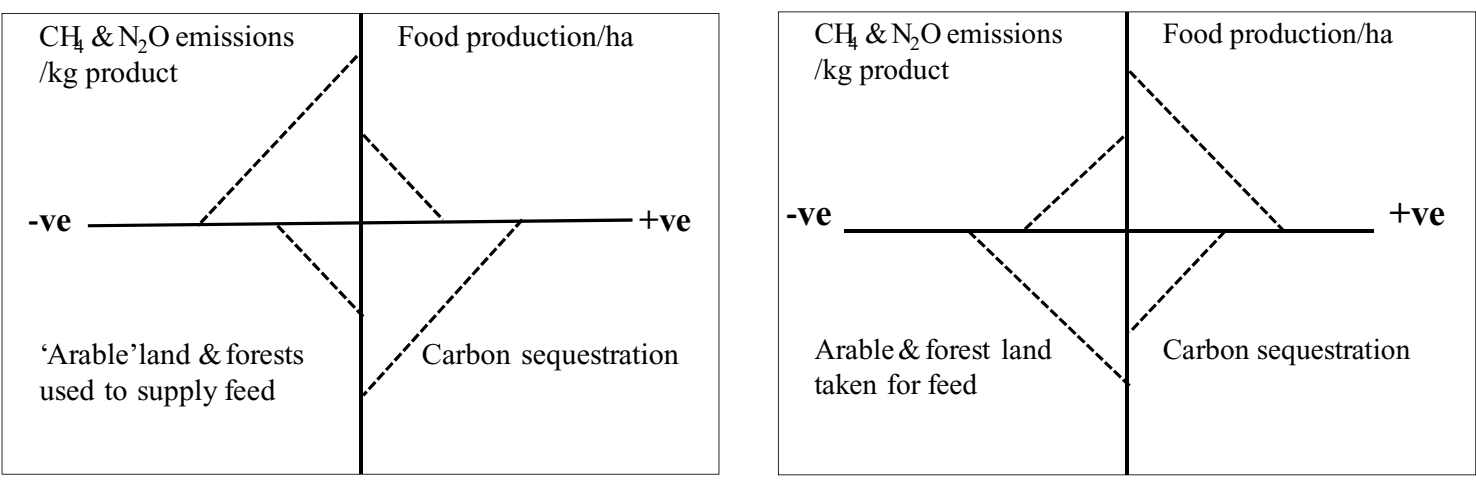

The challenge for herbivore scientists is to turn these qualitative appraisals into quantitative tools to provide a more balanced assessment of how to maximize the positives of herbivore contributions to food security, while minimizing the negatives.

\section{References}

FAO 2009. The State of Food and Agriculture: Livestock in the balance. Published by FAO, Rome.

Foresight. The Future of Food and Farming 2011. Final project report. The Government Office for Science, London.

Steinfeld, H., Gerber, P., Wassenaar, T., Castel, V., Rosales, M and de Haan, C. 2006. Livestock's long shadow. Environmental issues and options. Rome, FAO. 